\title{
Design and Development of Laboratory Network Management System Based on ASP.NET
}

\author{
Xu Pei \\ (NanChang Institute of Science and Technology, Nanchang, 330108)
}

\begin{abstract}
Keywords: ASP.NET; Laboratory Management; Design; Implementation
\end{abstract}
\begin{abstract}
With the increasing of students in colleges and universities, the laboratory need to face more and more students in different speciality and different administrative levels, that make the laboratory management work to become more and more complex. In order to reduce the management workload of laboratory, the combination of computer and information management technology is implemented, and which can not only help to carry out more reasonable, standardized and scientific management for laboratory but also help to comprehensively exert laboratory's effectiveness to improve the scientific research and teaching level of laboratory. Based on analysis of laboratory management system, this paper discusses the database design and the implementation of system based on ASP.NET technology and focuses on the design method and implementation.
\end{abstract}

\section{Introduction}

With the rapid development of university laboratory construction in recent years, the university laboratory has gradually began to open up, and the traditional laboratory management mode cannot have satisfied the requirements of laboratory education and management. A open laboratory management system can simplify the laboratory's open management process, improve the efficiency of use of laboratory and make students, teachers and laboratory staff to share the laboratory's information resources simply and quickly. Laboratory management system involves management of experiment teaching, instruments, project fund, security education and user information, and the design principle and target of laboratory management system can be understood on the basis of analysis of the system. For selection of laboratory management system platform, the design of data table and construction of database are involved in the data model of system. Practice and tests show that, the laboratory management system based on ASP.NET technology has some excellent functions such as convenient interface, high efficiency and good security, and can satisfied the interactive operation between every module.

\section{ASP.NET Technology and Laboratory Management}

ASP technology is the predecessor of ASP.NET technology. The operational framework of ASP.NET technology includes the flow of messages, the dispatch of messages and the processing of messages. This technology can not only be compatible with ASP in grammar but also provide new programming model and structure to produce application safer, scalable and steady. Secondly, the laboratory management mainly involves the processing of all kinds of data for project management, teaching arrangement, equipment management and personnel information. Especially when the annual workload account and the annual experiment arrangement are carried out, the data size may be very huge, and various statistical reports will be produced.

According to the real requirement, the laboratory management system can be divided into two parts back-end and front-end. In the back-end, manager can modify, delete and add data, and carry out the amalgamation of the data and produce various reports. The front-end mainly consists of the functions of login system, information inquiry and internal links.

\section{Requirements for Laboratory Management System}

The laboratory management system based on ASP.NET technology shall be simple for managers to query the equipment, basic situation, management system, personnel and experiment teaching of 
laboratory easily and quickly for realization of management and maintenance of laboratory equipment and carry out the management and maintenance for the personnel information of laboratory by adding, modifying and deleting the relevant maintenance records. In addition, this management system shall help the managers of laboratory to backup and restore data. The laboratory management system shall satisfy the manager's requirement of setting the login username and password and help the manager to modify his own login password for realization of the dynamic modification and restore of data.

\section{Design of Laboratory Teaching Management Platform}

\section{Overall System Architecture Design}

With this management system, the manager can configure the experiment environment, manage the basic information of teachers and students and view the laboratory reports of students. Students can make experiments and submit the laboratory reports by using this management system. (1) Students management module: students can submit their laboratory reports and view the relevant information. (2) Teachers management module: teachers can upload the experiment requirements, give students their marks and realize the reservation experiment and the communication and guidance with students. (3) manager management module: the manager can modify the information of teachers and students, examine and approve the experiments uploaded by teachers and add the names of teachers, classes and colleges. The system architecture of laboratory teaching management platform is shown in Figure 1.

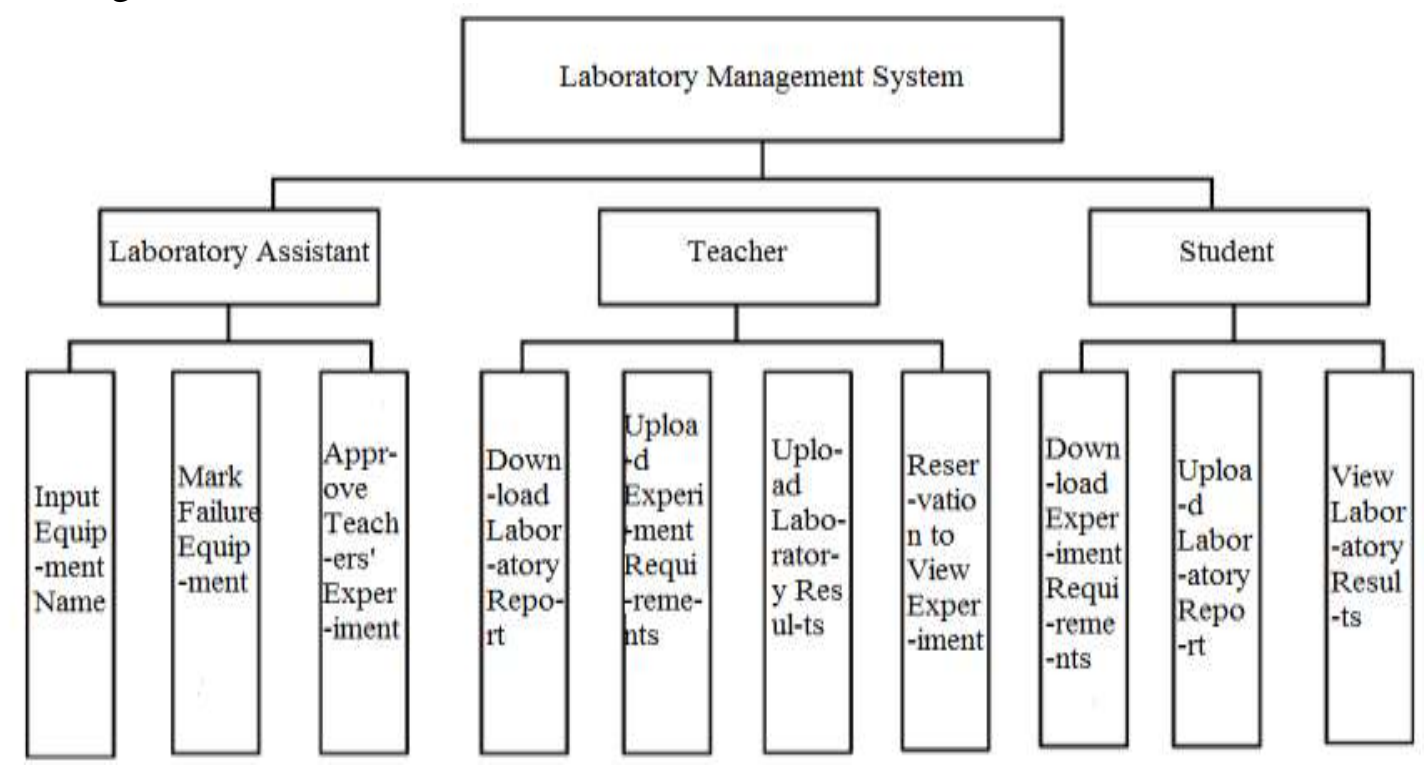

Figure 1. System Architecture of Laboratory Teaching Management Platform

\section{Main Functional Modules}

(1) Registration and login module: the user can login this system after registration. But the manager shall make a judgement according to real information of the user that the user can login this system only when his registration ID is consistent with the real ID.

(2) Students module: (1) information modification: students can modify their own personal information; (2) Experiment module: students can download the experiment requirements, submit their laboratory reports and view their own marks of experiment.

(3) Teachers module: (1) experiment management: teachers can add the relevant requirements for experiment information, download the laboratory reports submitted by students and give the corresponding marks; (2) personal information maintenance: teachers can modify materials, password and other information.

(4) Manager module: (1) student information management: the manager can modify, add and delete the name, student ID, sex and other information of students; (2) teacher information management: the manager can add a teacher and the information of teachers; (3) Experimental reservation module: when teachers have experiment tasks, they can inform the manager with the equipment required for 
experiment and the time to carry out the experiment reservation reasonably and efficiently. The experiment reservation module mainly includes the four factors which are the reservationist, reservation time, reservation class and the number of students for the experiment reserved.

\section{System Implementation}

The laboratory application based on ASP.NET shall include database, application server and Web browser. Data layer is the most low of the whole system which has the functions of providing the operational interface and storing the data. The application serer can be associated with the database to realize the deletion, modification and addition of the data as it is providing service for the browser. Web browser layer is the most high of the whole system. The user can operate the system through interface. The system modules are shown in Figure 2.
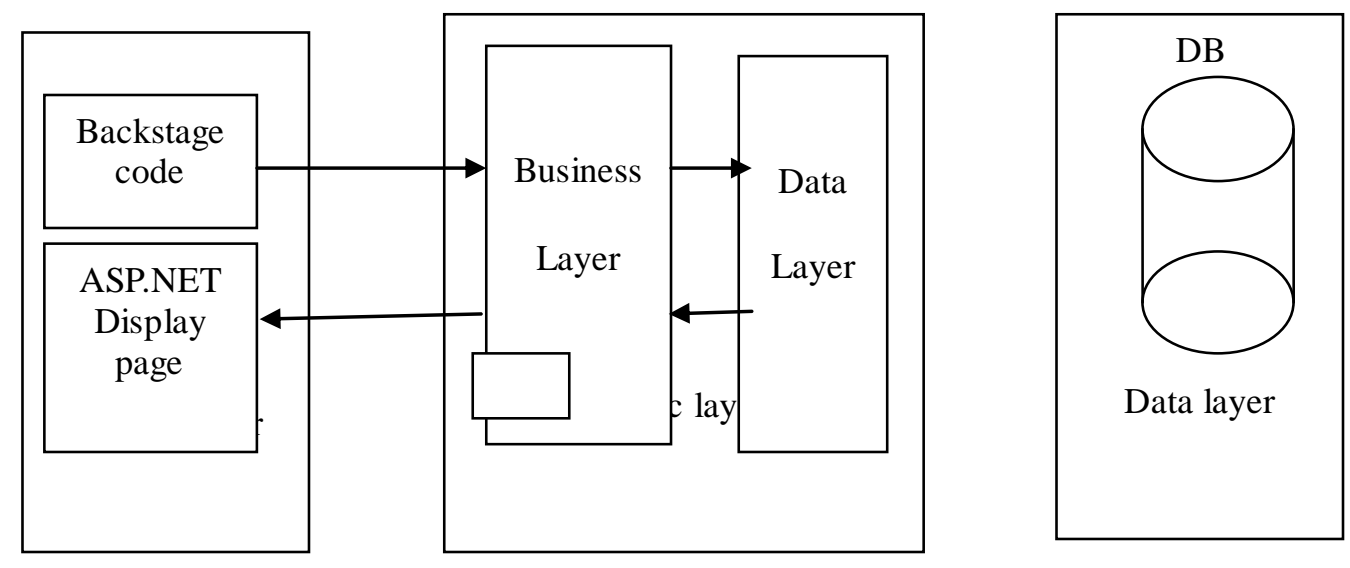

Figure 2. System Module Diagram

The main implementation operations are as follows.

\section{Design of System Data Model and Security System}

The design of system data model includes the design of data table, the description of data entity and the construction of database. In the design of data table, the main structure of data table shall be constructed with E-R model as the foundation. The design of security system includes assess control, user authentication and security log\&audit. Access control includes the permission to restore and modify the data, the permission to use the data resources and the permission to track the project fund. User authentication is mainly refer to the design of user login system. Security log\&audit is to monitor the data of log and control the time and operation requests.

\section{Database Technology}

In ASP.NET technology, the general purpose language shall be used to carry out the edition of the complex logic code and the computer-type task code, and the computer functions of the object-oriented shall be exerted such as encapsulation, polymorphism and inheritance. With the laboratory management system based on ASP.NET, the manager can organize the namespace, code and class to carry out the organization and maintenance for a lot of code in work. The function can simplify the development and management of database that the code can be organized to the namespace and assembly physically and logically.

\section{Database Design}

In the laboratory management system based on ASP.NET, the object-oriented method shall be used for the design of the table structure in database, and on the basis of operation of the table structure, the relevant operations of management system data shall be implemented. There are various tables in the database. Firstly, the information table of laboratory is mainly used to save the basic information of laboratory such as place, name and introduction. The project information table of laboratory is mainly used to store the information of experiment project. Secondly, the information table for manager is mainly used to store the basic information of managers, and the equipment information table is mainly used to store the basic information of experiment equipment. Thirdly, the arrangement table of laboratory and the application table of laboratory courses are 
mainly used to arrange and save the experimental teaching information to conveniently query the application information of teachers and students. In addition, the tables in database also includes teacher information table and equipment maintenance table, the former is used to store the information of teachers, the latter is used to store the maintenance records such as equipment maintenance, application and confirmation.

\section{Conclusion}

In summary, ASP.NET technology is upgraded from ASP technology. The laboratory management system based on ASP.NET can meet the needs of laboratory management, realize the centralized management, division of labor and coordination of work of laboratory management department, optimize the design of database and carry out the modification and addition of the data. In addition, the laboratory management system based on ASP.NET can help to realize the optimization of teaching management, the management of instruments and equipment and the management of personnel information, improve the level of management and carry out the further upgrade for the laboratory management system.

\section{References}

[1] Wang X Y, Dai S M. The Design and Development of the Online-Bookshop System Using Asp.net Technology[J]. Computer Knowledge \& Technology, 2007.

[2] Yang X M, Chen H L, Dong D Y. Development of asp.net Medley Mode Online Test System[J]. Research \& Exploration in Laboratory, 2007.

[3] Deng T. Optimization of Student Evaluation Information System Based on ASP.NET[J]. Applied Mechanics \& Materials, 2014, 608-609:286-290.

[4] Chun-Ying L I. Development of Scientific Research Information Management System Based on ASP.NET[J]. Journal of Chongqing Institute of Technology, 2007.

[5] Li,Juan. Research on the Marketing Management System Based on ASP.NET Technology[J]. Applied Mechanics \& Materials, 2014, 687-691:2387-2390.

[6] Hai-Liang L I. Design and Development of Invoicing System Based on ASP.net MVC[J]. Journal of Dongguan University of Technology, 2011.

[7] Wan R Z, Xin H. The Development of Student Information Management System Based on ASP.NET Workflow Technology[J]. Applied Mechanics \& Materials, 2014, 462-463(8):878-883.

[8] Zhou S. The Development of Management Information System Based on ASP.NET[J]. Computer \& Digital Engineering, 2007.

[9] Li Z X. The Development and Design of Online Examination System Based on ASP.NET[J]. Applied Mechanics \& Materials, 2015, 727-728:930-933.

[10] Wan R Z, Xin H. The Development of Student Information Management System Based on ASP.NET Workflow Technology[J]. Applied Mechanics \& Materials, 2014, 462-463(8):878-883.

[11] Yang L. The Development and Practice of Network Professional Certification System Based on ASP.NET[J]. Computer Knowledge \& Technology, 2016.

[12] Li D, Zhang B, Cheng C. Development of a vehicle monitoring system based on HTML and ASP.NET[C]// IEEE International Conference on Software Engineering and Service Science. IEEE, 2017:714-717. 